\title{
(2) OPEN ACCESS \\ Assistive technologies for ageing populations in six low-income and middle-income countries: a systematic review
}

\author{
Keshini Madara Marasinghe, ${ }^{1}$ Jostacio Moreno Lapitan, ${ }^{2}$ Alex Ross ${ }^{2}$
}

- Additional material is published online only. To view please visit the journal online (http://dx.doi.org/10.1136/ bmjinnov-2015-000065).

${ }^{1}$ School of Public Health, University of Saskatchewan, Saskatoon, Canada

${ }^{2}$ Innovation for Healthy Ageing, World Health Organization Centre for Health Development (WHO Kobe Centre), Kobe, Japan

\section{Correspondence to} Keshini Madara Marasinghe, School of Public Health, University of Saskatchewan; madara_m@hotmail.com

Received 17 June 2015 Revised 25 July 2015 Accepted 3 August 2015 Published Online First 11 September 2015

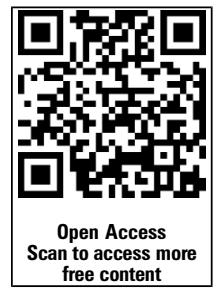

CrossMark

To cite: Marasinghe KM, Lapitan JM, Ross A. BMJ Innov 2015;1:182-195.

\begin{abstract}
Despite the benefits derived from the use of assistive technologies (AT), some parts of the world have minimal or no access to AT. In many low-income and middle-income countries (LMIC), only $5-15 \%$ of people who require AT have access to them. Rapid demographic changes will exacerbate this situation as populations over 60 years of age, as well as functional limitations among older populations, in LMIC are expected to be higher than in highincome countries in the coming years. Given both these trends, AT are likely to be in high demand and provide many benefits to respond to challenges related to healthy and productive ageing. Multiple databases were searched for English literature. Three groups of keywords were combined: those relating to AT, ageing population and LMIC selected for this study, namely Brazil, Cambodia, Egypt, India, Turkey and Zimbabwe. These countries are expected to see the most rapid growth in the 65 and above population in the coming years. Results indicate that all countries had AT designed for older adults with existing impairment and disability, but had limited AT that are designed to prevent impairment and disability among older adults who do not currently have any disabilities. All countries have ratified the UN Convention on the Rights of Persons with Disabilities. The findings conclude that AT for ageing populations have received some attention in LMIC as attested by the limited literature results. Analysis of review findings indicate the need for a comprehensive, integrated health and social system approach to increase the current availability of AT for ageing populations in LMIC. These would entail, yet not be limited to, work on: (1) promoting initiatives for low-cost AT; (2) awareness raising and capacity building on AT; (3) bridging the gap between AT policy and practice; and (4) fostering targeted research on AT.
\end{abstract}

\section{BACKGROUND}

According to the United Nations Department of Economic and Social Affairs' World Population Prospects, Brazil, Cambodia, Egypt, India, Turkey and Zimbabwe, are expected to see a rapid growth in the 65 and above population in the coming years (see online supplementary appendix A, table 1). Among low-income and middle-income countries (LMIC), Brazil, Cambodia, Egypt, India, and Turkey are expected to have the highest growth in 65 and above age group by the year 2050 and 2100 within each WHO region (see online supplementary appendix A, table 2). ${ }^{1}$ Zimbabwe, on the other hand, is expected to have the second highest growth among the LMIC in the WHO Region for Africa (AFRO) by 2050 and third highest by 2100 (see online supplementary appendix A, table 2). ${ }^{1}$ In addition to rapidly ageing populations, functional limitations (activity and participation restrictions) due to impairment and disability among older populations in LMIC are expected to be much higher than in highincome countries (HIC). Impairment is defined by the International Classification of Functioning, Disability and Health (ICF) as any loss or abnormality of psychological, physiological or anatomical structure or function. ${ }^{2}$ Disability is defined by the ICF as any restriction or lack (resulting from an impairment) of ability to perform an activity in the manner or within the range considered normal for a human being. With increasing age, older adults are more likely to experience impairment and disability that increase activity limitations where they may face difficulties in executing activities, and 
participation restrictions where they cannot become involved in social activities. ${ }^{2}$

For cognitive-related functional limitations, according to the World Alzheimer Report 2010, the growth in number of people with dementia in low-income countries is expected to increase from $\sim 35$ million in 2010 to $\sim 115$ million by 2050 , compared to HIC where the increase is expected to be from $\sim 15$ million in 2010 to close to $\sim 35$ million by $2050 .^{3}$ In 2012 , years lived with disability (YLDs) due to falls in adults aged 50-69 in developing countries (66\%) was nearly double the rate in developed countries (34\%). ${ }^{4}$ Falls have been documented as a key health concern leading to YLDs that older adults are facing today, and occur at home, in institutions and in the community. ${ }^{5}$

AT are defined as "the application of organized knowledge and skills, procedures and systems related to provision of assistive products, whose primary purpose is to maintain or improve an individual's functioning and independence, facilitate participation, and enhance overall well-being and quality of life."6 AT provide significant support and benefits for older adults in various ways: safety and prevention (ie, prevention of falls), mobility and independence, social connectivity and ease of living, preservation of cognitive abilities, delay in depression, decline in functional loss and improved well-being and quality of life. ${ }^{7-13}$ Safety has consistently been identified as one of the most important reasons for the use of AT among older adults. ${ }^{8} 10$ According to Heywood et $a l^{10}$ home adaptations have reported a $70 \%$ increase in feeling safe at home among older adults, while adaptations such as grab rails and handrails have been found to produce lasting positive consequences. A systematic review by Chase et $a l^{14}$ found that AT, home modifications, along with other interventions prevented falls among community-dwelling older adults. Evidence from the current literature suggest that more than half (62\%) of older adults felt safer from a risk of an accident with the availability of even minor adaptations. ${ }^{7}$ According to a study published by the AARP Foundation in the United States of America (USA), home safety devices made the majority of older adults feel safer $(85 \%)$ and gave them peace of mind $(78 \%){ }^{7}$
The definition of AT used in this review includes all the external technologies or products that are designed for and used by older adults. These technologies may assist in carrying out actions (ie, walking, bathing, remembering to take medications) and/or prevent severe health outcomes such as falls and injuries that may lead to more complicated health problems. There is a vast range of AT; according to the WHO, most of these products can be divided into several classes (table 1). ${ }^{6}$

AT are a fundamental part of broader, integrated health and social system solutions to supporting older adults. Yet, despite the documented benefits of AT, some parts of the world have minimal or no access to AT that are designed for older adults. According to the WHO, in many LMIC, only 5$15 \%$ of people who require AT have access to them. ${ }^{15}$ LMIC are expected to experience the most rapid and dramatic demographic change, in shortened timeframes as compared to higher income countries. For example, it took more than 100 years for the share of France's population aged 65 or older to double from $7 \%$ to $14 \%,{ }^{16}$ whereby it has been estimated that countries like Brazil will take less than 25 years to reach the same threshold. ${ }^{16}$ With rapidly ageing populations, accompanied by increasing functional limitations, in LMIC, AT are likely to be in higher demand.

Given the trends in LMICs, this review investigated the currently available AT, existing enabling legislation for provision of AT, and initiatives that promote AT for older adults in Brazil, Cambodia, Egypt, India, Turkey and Zimbabwe. The objective is to explore in the published literature, if currently available AT and existing legislation related to AT-provision are sufficient to support 'ageing in place' rather than ageing in institutionalised care homes; facilitate better health for older adults, especially in terms of functioning and independence (ie, carrying out Activities of Daily Living or ADLs and Instrumental Activities of Daily Living (IADLs)); encourage inclusion and full participation in community activities; and enhance older adults' overall well-being and quality of life.

Table 1 Classes of AT

\begin{tabular}{ll}
\hline Class & Product examples \\
\hline Products for cognitive functions & Memory devices and pill box reminders \\
Products for sensory functions & Spectacles, software for screen magnification and reading, hearing aids \\
Products related to orthotics and prosthetics & Artificial limbs (prosthesis), spinal orthotics and cervical collar \\
Products for personal mobility & Wheelchairs, canes and crutches \\
Products for activities of daily living (ADLs—see online supplementary & Toilet chairs, diapers and robots \\
$\begin{array}{l}\text { appendix B) including personal care and protection } \\
\text { Products for communication and skills training }\end{array}$ & Voice and speech training devices, Braille apparatus and screen readers \\
Products for recreation and sports & Modified sports equipment \\
Products for housing, work and environmental improvement & Home modification, handrails or grab bar and controlled lighting \\
\hline
\end{tabular}

AT, assistive technologies. 


\section{METHODS}

\section{Data sources and search strategy}

A systematic approach was taken to conduct the systematic review. The search strategy aimed to retrieve literature in English language that focused on AT to assist older populations (60 and above) in Brazil, Cambodia, Egypt, India, Turkey and Zimbabwe. Databases searched were MEDLINE (1950 to week 1 July 2014), EMBASE (1980 to week 1 July 2014), Scopus (1966 to week 1 July 2014) and Cochrane Library (1996 to week 1 July 2014).

WHO regional indexes including African Index Medicus (AIM); the Eastern Mediterranean Region Library Network (EMLIBNET); Pan American Health Organization (PAHO) Library Institutional Memory Database; Europe (EURO) publications; Index Medicus for South-East Asia Region (IMSEAR); WHO/WPRO Library; Western Pacific Region Index Medicus (WPRIM); and the WHO Library Database (WHOLIS) using the WHO Global Health Library platform were searched for relevant publications.

Three groups of keywords were combined: those relating to AT, ageing population and selected LMICs. Search terms used in each database are shown in figure 1. All retrieved articles were initially reviewed by title and abstract to find potentially relevant papers. Those papers were reviewed to obtain articles that met the inclusion criteria. Reference lists of articles that met the inclusion criteria were reviewed to identify any further relevant papers.

\section{Study selection-Inclusion criteria}

Selected papers were assessed against the following inclusion criteria: (1) studies published in academic and peer-reviewed journals, research reports, government reports (2) studies answered 'yes' to all three screening questions (3) written in English.

Screening Questions:

I. Does the publication address AT as a primary research topic?

II. Does the publication focus on one of the six countries?

III. Does the sample size or intended population include older adults ( $\geq 60$ years old)?
Study selection-exclusion criteria

If the abstract indicated that the study did not relate to AT for ageing populations in LMICs, the study was excluded (ie, material relating to disability studies involving only younger people). Studies that focused on the technology use in hospitals were excluded, since the rationale of the systematic review is to focus on AT that have a direct impact on older adults to enhance their ADLs and participation in the community and at home. Duplicates were excluded (figure 2).

\section{RESULTS}

The systematic review retrieved 17 relevant studies; four studies related to AT in Brazil, seven related to India, three related to Turkey and one study per each country for Cambodia, Egypt and Zimbabwe (figure 3). Seven publications focused on 'mobility' AT while six on 'more than one function'; and AT for cognitive functions, ADLs, vision and others had one citation each (figure 4). Relevant studies are classified into four types as provided in table 2 below. Tables $3-5,{ }^{17-33}$ provide an overview of relevant studies, existing enabling legislation and findings on AT for each country, respectively.

\section{AT- related National Initiatives \\ Brazil}

The Assistive Technology Innovation Programme (PITA) finances technological development and innovation of products, processes and services targeted at people with disabilities, older adults and as well as others with difficulties of mobility. ${ }^{49}$ A budget of US\$70 million is anticipated for this programme until 2014 directed to 'innovation activities' carried out by companies, universities and research institutions. Innovation activities include development and/or enhancement of products, processes and services related to AT and/or contribution toward prevention, alleviation or elimination of deficiencies. ${ }^{49}$

Future plans include the establishment of the National Centre for Excellence in Adaptive Technology, composed of 20 research centres implemented in public universities to develop strategic technologies, with an emphasis on prevention,

\footnotetext{
Scopus (1966 to July 2014) and Cochrane Library (1996 to July 2014) included: (TITLE (assist* OR technolog* OR "assistive device*” OR “assistive product*" OR innovation OR "assistive technolog*" OR gerontechnology OR "low cost assistive technology" OR telecare) AND ABS (aged OR "older adult*" OR senior* OR "old* people" OR elder* OR disabilit* OR disabled OR geriatric OR frail) AND ALL (Brazil OR Cambodia OR Egypt OR India OR Turkey OR Zimbabwe))

EMBASE (1980 to July 2014): exp assistive technology/ AND exp Brazil/ OR exp Cambodia/OR exp Egypt/ OR exp India/ OR exp Turkey/

MEDLINE (1950 to July 2014): (((self-help device*[MeSH Terms]) OR gerontechnology OR innovation* AND aged[MeSH Terms] AND (brazil OR Cambodia OR Egypt OR India OR Turkey OR Zimbabwe))
}

Figure 1 Search terms used in each database. 


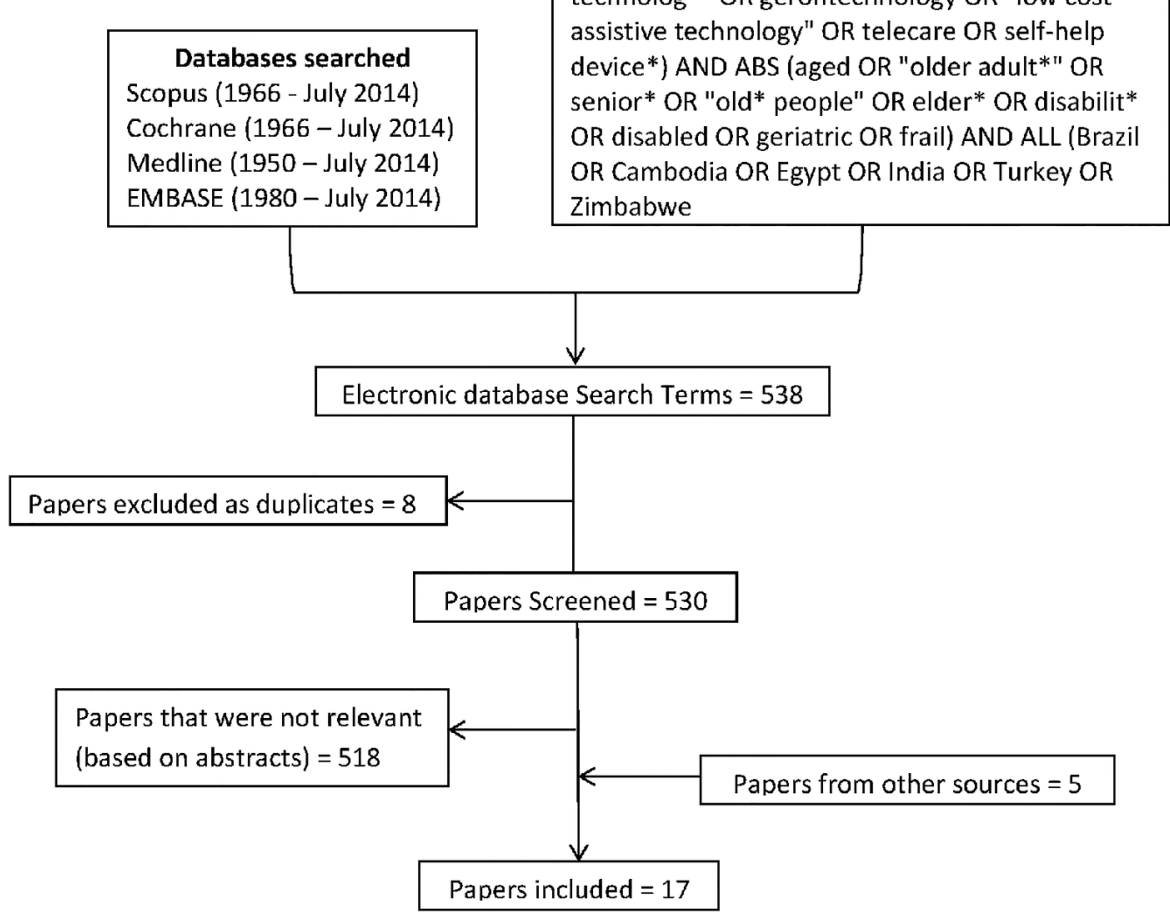

Search Terms

assist* OR technolog* OR "assistive device*" OR

"assistive product*" OR innovation OR "assistive technolog*" OR gerontechnology OR "low cost assistive technology" OR telecare OR self-help device*) AND ABS (aged OR "older adult*" OR senior* OR "old* people" OR elder* OR disabilit* $O R$ disabled OR geriatric OR frail) AND ALL (Brazil OR Cambodia OR Egypt OR India OR Turkey OR

Medline (1950 - July 2014)

EMBASE (1980 - July 2014)

Papers included $=17$

Figure 2 Literature search.

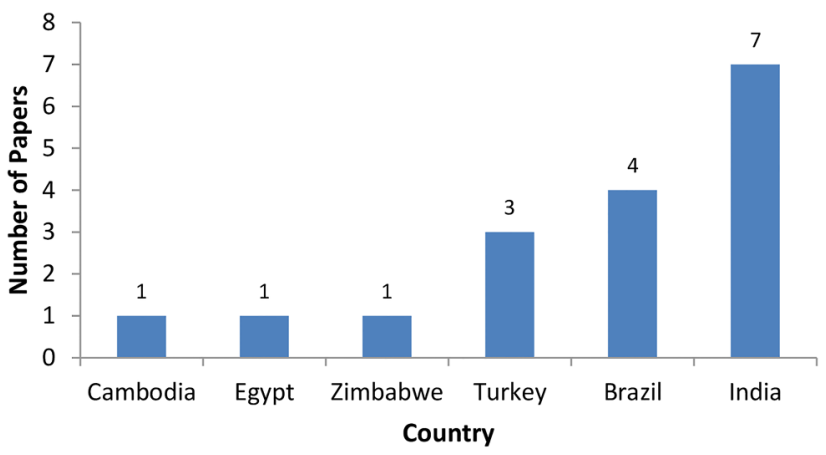

Figure 3 Number of publications retrieved by country.

rehabilitation and accessibility. The programme launched a virtual catalogue of more than 1200 AT products available in Brazil (http://assistiva.mct.gov. br). ${ }^{34}$ The website is to be updated at least once a year, so consumers and professionals are aware of availability of AT products in the country. ${ }^{34}$

\section{Cambodia}

Phnom Penh's National Component Factory is the only source of Prosthetic and Orthotic (P\&O) devices in the country. It monitors and evaluates the production of prosthetics and AT materials, in order to supply for workshops and centres that produce P\&O. ${ }^{50}$ They supply close to 15000 those in need a year. Since January 2009, Phnom Penh's National Component Factory has produced and supplied more



Figure 4 Number of publications by assistive technologies category.

than 3000 artificial limbs, knee joints and alignment systems to physical rehabilitation centres in the country, free of charge. ${ }^{51}$

A number of workshops are available to provide prostheses, wheelchairs and crutches, repair and maintenance services in Cambodia, where each workshop is operated in partnership between the Government and NGOs. Currently 21 workshops provide AT for people with locomotor disabilities. Some of the workshops are run by numerous associations, committees and organisations. Online supplementary appendix E provides an overview of the associations and services provided. 
Table 2 Study classification

\begin{tabular}{ll}
\hline Study type & Description \\
\hline Research & Includes all types of research studies \\
Product development & Project focusing on the development/production of \\
and intervention & AT and intervention to assess product impacts \\
Product development & Merely production or development of AT \\
Product evaluation & Evaluation of products \\
\hline
\end{tabular}

AT, assistive technologies.

\section{Egypt}

In Egypt, non-governmental organisations (NGOs) such as the Egyptian Society for Elderly Care and Misr al-Kheir provide assistance in acquisition of ATs such as canes and wheelchairs. ${ }^{48}$ The Arabic Doctors' Union (an NGO) provides hearing aids and cochlear implants to those of age 65 and above while the Egyptian Society for Hearing Impaired Persons is responsible for provision and training the use and maintenance of hearing aids. ${ }^{48}$ Furthermore, Wafaa and $\mathrm{Amal}^{48}$ compound established and run by the Egyptian Veterans Association includes an assistive device factory for manufacture, maintenance and some export of devices for disabled individuals and veterans, where majority are older adults.

The government contributes to the provision of AT through the development, production, distribution, maintenance and repair. The government also provides prostheses/orthoses, wheelchairs, crutches, hearing devices and visual devices. ${ }^{52}$ In addition, the Ministry of Health and the Ministry of Social Solidarity provide healthcare and rehabilitation services, including technical aids and devices through their institutions. Ministry of Social Affairs provides services such as physiotherapy, prosthesis and assistive devices and rehabilitation.

\section{India}

The Artificial Limb Manufacturing Company (ALIMCO), fully supported by the Government of India's Ministry of Welfare, manufactures a large number of tools, machines and components for producing AT and finished devices. So far, ALIMCO has provided AT to 4.2 million users in India and serves approximately 200000 users annually. ALIMCO also provides AT to Afghanistan, Nepal and Bhutan among others. ${ }^{53}$

The Indian Drugs and Pharmaceuticals Ltd. is the only other Indian company that manufactures components for AT in large numbers. ${ }^{54}$ In addition, there are at least 15 agencies producing wheelchairs and 20 producing tricycles. ${ }^{54}$ The most commonly produced are hearing aids, by as many as 32 manufacturing agencies mainly in the private sector. ${ }^{54}$

Most of the time, AT are distributed through NGOs, district rehabilitation centres, medical colleges and hospitals, special schools and camps and national institutions in India. NGOs and government supported institutions have spread over 19 states and union territories, which are financially supported under the ADIP Scheme run by the Government's Ministry of Welfare. ${ }^{54}$ The Department of Rural Development is involved in distribution efforts, and some NGOs not supported by the government also give out assistive devices. As many as 25 out of 31 states and union territories have their own schemes of providing AT through government hospitals and voluntary agencies. ${ }^{54}$ Many district rehabilitation centres also provide AT in the rural areas of specified regions.

The Government of India launched the scheme of Science and Technology-Project in Mission Mode 1988 , to provide suitable and cost-effective aids and appliances and improve mobility. ${ }^{54}$ The project concentrated on developing cost-effective technologies and appliances and guiding these to large-scale use. Furthermore, there are initiatives to encourage proposals, research and development of technological solutions for older adults. One such example is the Initiative on Science and Technology Interventions 2010 for the elderly population, introduced by the Department of Science and Technology, under Science for Equity, Empowerment and Development Division (SEED). The initiative included a number of valuable indicatives (see online supplementary Appendix F). ${ }^{55}$

\section{Turkey}

No further initiatives were found.

\section{Zimbabwe}

No further initiatives were found. However, assistive devices and equipment for persons with disabilities are partially financed by Government Ministries, persons with disabilities and NGOs. The Government of Zimbabwe is involved in the provision of assistive devices, and provides prostheses/orthoses, wheelchairs, crutches and hearing devices. ${ }^{56}$

\section{DISCUSSION}

The systematic review found that AT designed for older adults, have received some attention in LMIC. The publications $(n=17)$ retrieved, heavily focused on products that assisted older adults with existing impairment and disability and only a few projects ${ }^{172022} 2430$ focused on AT designed for preventing impairment and disability among older adults (ie, fall preventive devices or smart home technologies). While existing disability related AT (eg, prosthetics, orthotics) are somewhat available in LMIC, other products designed to prevent impairment, disability and other health outcomes among older adults have received minimal attention, putting aside the needs of older adults who do not have existing disabilities but are at risk for developing impairment and disability due to increasing age, who would otherwise benefit from AT. Therefore, AT for the entire ageing populations including older adults with disabilities and older adults without existing disabilities but are at high risk 
Table 3 Table of Evidence

Country,

Author, Year
Study Type/Data

Collection Method
Relevant Outcomes Regarding Available AT and Other Findings
Population Description

\section{Brazil}

Assis et al, N/A $2003^{9}$

$$
2013^{3}
$$

Mello MAF, $\quad \mathrm{N}=84$, Age range $=73-102$ $1999^{17}$

Schüler, et al $2013^{5}$

Jones et al, $2003^{7}$
De Cruz et al, $\quad \mathrm{N}=91$, Mean Age $=62.2$

\section{Cambodia}

$\mathrm{N}=100$ (Disabled, non-disabled adults, and disabled children). Results only focused on older adults.
Product development and intervention, and Product evaluation

Research Cross-Sectional

Research (Doctoral Thesis) N/A

Product development

Research

Qualitative study (In-depth field work Semi-structured interviews and observation)

Product development

\begin{tabular}{|c|c|}
\hline $\begin{array}{l}\text { Salah et al., } \\
2011^{10}\end{array}$ & $\mathrm{~N} / \mathrm{A}$ \\
\hline \multicolumn{2}{|l|}{ India } \\
\hline $\begin{array}{l}\text { Jefferds et al., } \\
2010^{6}\end{array}$ & $\begin{array}{l}\text { PART survey age range }=19-67 \text {,WST/ } \\
\text { QUEST age range }=21-60\end{array}$ \\
\hline $\begin{array}{l}\text { Kumar et al, } \\
2009^{12}\end{array}$ & $\begin{array}{l}\mathrm{N}=100, \text { Age }=60-85 \text { years, Mean } \\
\text { Age }=\mathrm{N} / \mathrm{A}\end{array}$ \\
\hline
\end{tabular}

Langdon et al., $\quad \mathrm{N}=19$, Age range $=25-84$ $2013^{8}$

Manogna S et al., $2010^{13}$
N/A
Research

Quantitative Study (Survey Questionnaire)

Research

Qualitative Study (Survey Questionnaire)
Research Qualitative Study (Semi-structured Interview)

Product Development

Development of low-cost "Geriatric" software and equipment (activity board, calendar, routine organizer). Software and equipment were found useful and applicable to programmes for individuals with cognitive impairment. Post intervention showed improvement in cognitive functioning and daily activities at home.

Most reported assistive resources were those to assist mobility (46\%) (Predominately canes), and ADLs (29\%). No direct association between AT and independence (only mild dependency).

$74 \%$ of participants used some type of AT. Canes were the most used type of AT (45\%).

$4 \%$ of the participants had all the assistive devices and home modifications they needed.

$35.5 \%$ of users were satisfied with the use of these technologies.

$2 / 3$ of the AT were purchased by the user, a relative, or friend.

Produced low-cost AT such as cane tips to detect puddles, Android application for social media websites (i.e. Twitter), capacitive touch switches, home automation systems with web interface, $A A C$, and digitally creating video audio descriptions for a lower cost.

Most had access to AT for bathing, drinking, toilet use, and transporting water from the source.

Majority of solutions were low or no cost, made with locally available material and designs.

AT benefited disabled individuals in terms of increased self-reliance, ability to contribute to the family or community, improved social status, reduced work-load, well-being, economic situation, and high self-esteem.

Development of the EJAD, low cost AT to help older adults walk and complete sit-to stand activities.

Custom-fitted wheelchairs provided by the Department of AT improved wheelchair skill scores and technology satisfaction among participants.

Inadequate availability of AT in India has been partially due to the lack of awareness among the users as well as among the professionals.

Although respondents lacked awareness of the devices, they were willing to use them, provided these are made available at affordable costs.

$27 \%$ had difficulty in the kitchen gadgets and appliances, $26 \%$ in recreation/entertainment, $21 \%$ in home elements, $19 \%$ with mobility and $18 \%$ with ADLs.

Highest awareness was in communication devices, home elements, ADL mobility, and least was in high-tech AT.

Participants with impairments were enthusiastic to use new technical devices, but emphasized on need of training.

Many users did not have access to assistive devices and interaction techniques.

Development of head movement based assist system to serve people with quadriplegia.

The assist system has proven to be of simple implementation and of low cost.

The system was easily handled by the patients. 


\section{ASSISTIVE TECHNOLOGIES}

Table 3 Continued

\begin{tabular}{lll}
\hline $\begin{array}{l}\text { Country, } \\
\text { Author, Year }\end{array}$ & Population Description & $\begin{array}{l}\text { Study Type/Data } \\
\text { Collection Method }\end{array}$ \\
\hline Shore, $2008^{14}$ & $\mathrm{~N}=100$ (from India), Mean Age=50 \pm 25 & $\begin{array}{l}\text { Research } \\
\text { Age range=3-93 }\end{array}$ \\
& Quantitative Study (Survey)
\end{tabular}

Shore $S$ et al, $\quad \mathrm{N}=206$, Mean Age $=54$, Age

$2012^{15} \quad$ range $=4-102$

Zipfel, et al., N/A

$2007^{4}$

\section{Turkey} $\begin{array}{rl}\text { Bengisu, } 2010^{2} & \mathrm{~N}=80, \text { Mean } \mathrm{Age}=35 \pm 9 \\ & \text { Age range }=18-61\end{array}$

Simsek et al., $2012^{16}$

$\mathrm{N}=163$, Mean age $=73.18 \pm 6.62$, Age range $=58-105$

Ucsular et al., $\quad \mathrm{N}=24$, Age range $=13-65$ $2011^{11}$

\section{Zimbabwe}

Edie et al $2003^{1}$
$\mathrm{N}=3901$ households, Mean Age

(Disability) $=43.2$

Age range $=0-98$

Matabeleland, Manicaland and Midlands ( $44 \%$ of the total population).
Research

Quantitative Study

Survey

Product Development

Research

Qualitative Study

(Phone interview) Product evaluation

Research

Quantitative and qualitative Study (mixed methods)

Research

Randomized Control Trial

Research

Qualitative Study (Survey
Relevant Outcomes Regarding Available AT and Other Findings

Use of wheelchair resulted in significant shift towards independent function.

The impact on health and quality of life was generally viewed as positive $(56.2 \%)$.

Receiving a simple and durable wheelchair improved the reported health, quality of life, and function of recipients following 12 months of use.

$78 \%$ had not owned a wheelchair before, largely due to lack of money.

Increase in independence associated with the use of wheelchair (independence score changed from 3.9 to 5.0 over 12 months).

Developed a manual folding cross-brace design with several points of adjustability, and higher grade bolts. The new chair design has so far proven to be more durable and comfortable than existing wheelchairs.

Three most used AT were computer screen readers (46\%), talking watches $(26 \%)$, and screen readers for cellular phones (21\%).

Most desired AT were cellular phones with screen reading capability.

Most frequently requested AT were devices for warning about barriers, reading printed documents and signs. Screen readers for computers were rated the highest (4.7) 5) and $76 \%$ of the participants rated them very useful and 0 participants rated the product not useful.

Screen readers for cellular phones were rated $4.6 / 5$ and $72 \%$ of the participants rated them very useful and only $1 \%$ rated it not useful.

The most frequently used device to maintain mobility was a walking stick.

A positive relationship was found between AT usage and mobility state, and AT usage and mobility activities required for developing basic life functions $(P<0.05)$. AT usage was greater in women (39\%) than in men (19\%).

The Wheelchair Skill performance scores increased significantly in the training group $(P=0.034)$ compared to control group $(P=0.01)$.

A significant improvement in safety scores in the training group compared with the control group.

Of those who used AT, $41.7 \%$ were among $\geq 61$. Of those who used AT, $80 \%$ used personal mobility devices, 19\% used AT for communication and information, $2.2 \%$ of the users had AT for personal care \& protection. $31.2 \%$ of the devices were provided by private sources, $27.4 \%$ from government health services, $8.3 \%$ from NGOs, $3.2 \%$ from other government services and $28.8 \%$ from other sources.

$63.1 \%$ received guidance on using the devices, 36.9\% had not received any instructions. Significantly fewer disabled in rural areas had received guidance; $57 \%$ versus $73 \%$ in urban areas.

$36.3 \%$ were responsible themselves for maintenance and repair, $14 \%$ had government assistance, $21 \%$ relied on families and $14 \%$ had devices not maintained or repaired.

Zimbabwe had the smallest gap in AT/services compared to 3 other African countries (Malawi, Namibia, and Zambia).

$35.1 \%$ urban Zimbabweans had access to AT compared to $22.2 \%$ rural populations. 
Table 4 Overview of legislation/national plans/policies and acts

\begin{tabular}{|c|c|}
\hline Country & Legislation/national plan \\
\hline $\begin{array}{l}\text { Ratified by all } 6 \\
\text { countries }\end{array}$ & $\begin{array}{l}\text { UN Convention on the Rights of Persons with Disabilities } \\
\text { (CRPD) }\end{array}$ \\
\hline $\begin{array}{l}\text { Ratified by } \\
\text { Brazil } \\
\text { and Zimbabwe }\end{array}$ & CRPD Optional Protocol (OP-CRPD) \\
\hline
\end{tabular}

Significance

Online supplementary appendix C, UN CRPD

Allows for individual complaints to be submitted to the CRPD Committee alleging that rights have been violated under CRPD.

If the CRPD Committee makes a finding that the State has failed in its obligations under the CRPD, it will issue a decision requiring that the violation be remedied and for the State party to provide follow-up information

Brazil Decree No. 7612

Law 10 048/2000

Decree No. 5296 Chapter VII, Article 64, 65 and 66

Decree No. 4360

Cambodia National Policy on the Health Care for Elderly and Disabled People 1999

Protection and Promotion of the Rights of Persons with Disabilities (PPRPD), Article 4, 20 and 26

Disability Action Council (DAC) Royal Sub-Decree No. 59, 2009, PPRPD

India The National Policy for Persons with Disabilities 2006

Persons with Disabilities (Equal Opportunities, Protection of Rights and Full Participation) Act 1995

Scheme of Assistance to Disabled Persons for Purchase/Fitting of Aids/Appliances (ADIP Scheme) 2005 (see online supplementary appendix D)

India's National Policy on Senior Citizens 2011

Turkey

Turkish Disability Act Law no. 5378/2005, Article 3 and 7

Value Added Tax (VAT) Law No. 3065, Article 167-4/4 and $17 / 4$
Rights of Persons with Disabilities (PWDi) -Living Without Limits Plan. Promote accessibility for people with disability and frail adults through:

- Credit lines for the acquisition of AT

- Institutionalisation of the National Programme for AT

- Tax rebate on AT products. ${ }^{34}$

Reduction or exemption from import taxes for products that are not available within the country.

Reduction or exemption from excise tax on technical aids.

Deduction of income tax for all AT for people with disabilities or reduced mobility. ${ }^{35}$ Recognize the area of AT as an area of knowledge.

Encourage the formation and training of orthotics and prosthetics.

Encourage studies to support the development of standards on technical aids.

Detection of regional reference centres for technical aids, aiming at the formation of an integrated national network ${ }^{35}$

Provision of long-term assistance for people with disabilities and older people ${ }^{36}$

'Further plan of action' states that providing the elders and disabled to obtain the AT such as hearing aids, walking aids and kitchen utensils to assist living independently as one of the priorities for social protection ${ }^{37}$

Commits to: Giving priority to technologies at an affordable cost.

Providing accessible information to persons with disabilities about available AT, including new technologies, as well as other forms of assistance, support services and facilities.

Facilitating access to quality mobility aids, devices, AT and forms of live assistance and intermediaries.

Encouraging entities that produce AT to take into account all aspects of mobility for persons with disabilities

Promoting the availability, knowledge and use of AT designed for PWDi ${ }^{38}$

Involved in standardisation through subcommittee on prosthetics, orthotics and

assistive devices and give advice and orientation at the national level

Provides recommendations for the rights of persons with disabilities

Endorsed in the law on the PPRPD, and receives core funding from USAID through its humanitarian assistance budget ${ }^{39}$

Physical Rehabilitations Strategies under Rehabilitation measures includes provision of AT as one of the commitments

Commits to creating an environment that provides Persons with Disabilities equal opportunities, protection of their rights and full participation in society ${ }^{40}$

The 'education' component suggests research for designing and developing new AT Governments shall initiate/encourage research by official and non-governmental agencies to design and develop new AT

'Research and manpower development' promotes sponsoring research in the development of $\mathrm{AT}^{41}$

Assist low income individuals with disabilities in obtaining assistive aids and appliances

Those aids/appliances which do not cost more than US\$100.46 are covered

Those with income US\$250 to US\$333/month receive devices at a $50 \%$ subsidy

Those with incomes of US $\$ 250 /$ month, receive devices at full cost ${ }^{42}$

Provide 500 Cochlear implants free per year

Increasing advancement in technology is one of the listed priority areas

Highlights that technology is not only needed for the $\geq 80$, but also for rural poor, disadvantaged seniors who will have longer years in the coming decades ${ }^{43}$

Commits to having buildings, open space, transportation and information services and information and communication technology, accessible and usable by people with disabilities to be safe and independent

Commits to disclosure of information and communication technologies and services to be accessible for people with disabilities

Provides importation exemptions within the scope of customs law article 167-4/4 and general goods for the disabled

Provides partial exemption for delivery of computer programmes and every kind of instruments (excluding vehicles), and equipment especially produced for daily life of the disabled. ${ }^{44}$

The services provided in elderly and disabled care houses are considered exceptions and the services provided in such places are also held exempt from the value added $\operatorname{tax}^{45}$ 


\title{
ASSISTIVE TECHNOLOGIES
}

Table 4 Continued

\begin{tabular}{ll}
\hline Country & Legislation/national plan \\
\hline & Social Assistance and Solidarity Law No. 3294, Article 5
\end{tabular}

Significance

Covers the costs of treatment and function-acquisition related orthopaedic and other aid tools/equipment for PWDi who are covered by social security institutions and get salary or payment from institutions ${ }^{46}$

Zimbabwe National Disabled Persons' Act 1992, Section 4

Established the National Disability Board that is responsible for the formulation and development of measures and policies to ensure that disabled people live independently and access all social services, and estimation of the cost of the measures for the welfare and rehabilitation of disabled persons ${ }^{47}$

Disabled Persons Fund (DPF)

Provides public assistance, medical fees, purchases assistive devices and a revolving loan facility

Allows exempt from the payment of import tax for all specially adapted cars purchased

Ensures that disabled people are assisted with the purchase of AT like crutches, artificial limbs, spectacles and wheelchairs to enable carrying out day to day functions $s^{47}$

Social Welfare Assistance Act of 1988

Provides for the health provision, maintenance allowances, purchase of AT, import of special equipment for the disabled to assist in their daily activities, means tested criteria for the assessment of poverty among vulnerable groups ${ }^{47}$

Government provides for a waiver of duty for all specially adapted for use by

Customs and Excise Regulations 2004 persons with disabilities imported less than 5 years from the date of manufacture ${ }^{47}$

AT, assistive technologies.

for impairment and disability, such as those who are living alone at home, are necessary.

Based on the country-level findings and an overall analysis of all materials gathered for this systematic review, a set of high-level findings are presented and discussed below that could be considered as broad action points in moving forward with the relevant agenda on AT for ageing populations in LMIC.

\section{Promoting initiatives for low-cost AT}

In many LMIC, production of AT is low; where access might be possible, costs are excessive. ${ }^{15} 20$ However, this systematic review found that of those LMIC that have AT initiatives in place, typically for disabled populations, many have started the production of low-cost AT (ie, Brazil, Cambodia, Egypt and India). In Cambodia, the majority of the technological solutions provided included low-cost or even, no-cost AT, which are produced by using locally available materials and designs. ${ }^{50}$ The construction of low-cost equipment in Brazil is a model example, where production cost of devices was 30\% lower compared with the cost of imported equipment. ${ }^{20}$ In the past 5 years, Assistive Technology Centers in Brazil have been

Table 5 Findings on AT availability by country (cited at least once in publications)

\begin{abstract}
Country Assistive technology
Brazil Canes, wheelchairs, walkers, bath chairs, toilet chairs, hearing aids, 'Geriatric' software, activity board, calendar, routine organiser, cane tips to detect puddles, Android application to access social media websites (ie, Twitter), capacitive touch switches, home automation systems with web interface, augmentative and alternative communication devices (AAC) and digitally creating video audio descriptions, Braille display, button mouse, audio transmitter, capacitive driver, cane tip for water detection ${ }^{17-20}$

Cambodia AT for locomotor disabilities, weaving kits, bamboo walking canes, wheelchairs, crutches, tricycles, prostheses, artificial limbs, knee joints, double gripping hook/bowl attachments for prosthetic arm, carved wooden carrying yokes, chairs with an attached trays, wooden bathing benches with rails at each end, metal/rubber bathing benches, wheelchair jump seats, wooden toilet seats with handrails on each side, wheelchair toilet seats and soft plastic washing devices to clean self after toilet use and different forms of seating ${ }^{21}$

Egypt Egypt-Japan Assistive Device (EJAD), a low-cost AT designed to help elders in walking and sit-to-stand activities. ${ }^{22}$ EJAD imitates the caregiver's motion during a support task, which helps maintain the stability of the users at any situation, Tablet PCs powered by Android systems containing Quran in large font, cooking recipes, and old songs and Cellular phones with large buttons ${ }^{48}$

India Security alarms, raised seat, grab bars, video intercom, medicine dispenser/cabinet, Jar opener/closer, talking alarm clock/watch, magnifying toenail clipper, lap desk with book holder, back scrubber with hand loops on each end, kitchen finger protector, utensils with finger bump grips or hand strap, adjustable height bed, bed rail, Velcro fastenings shoes, Velcro clothing, pressure modification stockings, cordless speaker phone with pre-set memory-dial, large buttons and numbers, mobile phone with one touch call to family members, friends, helplines, doctors, security, eye glasses/magnifiers, 'E-Netra' reads text and converts into voice, hearing aids, visual alerting systems, memory games, walking stick, walkers, wheelchair, spinal braces, stair glide, handrails, prosthesis-artificial limbs, height adjustable/tilting chairs/stool/tables/desks, CDs on traditions, historic movements, pilgrimage and tourist places, folk songs, wheelchair and head movement-based assist system ${ }^{23-29}$
\end{abstract}

Turkey Reading pens, screen readers for cell phones, and computers, locators, laser canes, modified appliances, talking watches, walking sticks, crutches, walkers and wheelchairs ${ }^{30-32}$

Zimbabwe Wheelchairs, walking sticks, crutches, standing frame, white cane, eye glasses, magnifying glasses, hearing aids, Braille, portable writer and enlarged print, bath and shower seats, commode chairs, toilet seat raisers, safety rails and eating aids, aids for opening containers, flashing light on doorbell, vibrating alarm clock and amplified telephones ${ }^{33}$

AT, assistive technologies. 
developing AT similar to the commercial products, but with use of low-cost material and price reduction of up to $70 \%$ (see online supplementary appendix G, table 6). ${ }^{34}$ Strategies such as producing low-cost products by using locally available materials increase potential for continuous growth and demand for AT and allow for mass production to all those needing them. It is one of the most suitable strategies for LMIC, and highly recommended for resource-poor contexts. ${ }^{57}$ Mass production can lower costs if the technologies follow universal design principles and are marketed widely. ALIMCO in India is an example where large amount of AT are produced and marketed internationally. ${ }^{53}$ In the countries that have large production, markets should be expanded beyond regional boundaries to allow for cost advantages, operational efficiency and lower variable costs. In particular, there is a priority need for producers of AT to tailor design, distribution and cost to the realities and demand of older adults.

In terms of production, many LMIC produced AT locally. Cambodia and India produce a considerable number of AT and components for AT with materials indigenous in these countries. This may be partly explained by the fact that the production workshops or companies themselves are partially or fully supported by or working in partnership with the government. Providing funds for local workshops such as the Egyptian Fund for Supporting Small Industries, ${ }^{48}$ further encourages local production. Manufacturing or assembling products locally, using local materials, can ensure that devices are suitable for the context. ${ }^{58}$ It may either be a locally produced, finished product or locally assembled products with imported materials. Where local production is not sustainable, reducing import and duty taxes on AT devices or components can help reduce costs. For example, Brazil does not impose import or duty taxes on imported materials, ${ }^{59}$ Turkey has exemptions for imported goods and partial exemptions for selected equipment, and Zimbabwe also allows for exemption from paying import tax for some equipment produced for older adults and disabled citizens. ${ }^{45}$ Therefore, local production and reduction of taxes, where import is required, are appropriate strategies that governments can acknowledge and support.

\section{Awareness raising and capacity building on AT}

Producing and providing AT in and of themselves is not adequate. Significantly fewer AT users in rural areas receive guidance and instructions on the use of AT, and only a few older adults are aware of the existing AT and their benefits in LMIC. For example, a major constraint to the availability of AT in India has been partly the lack of awareness among the users and professionals. ${ }^{24}$ Even if schemes are available to provide free or subsidised AT, unless users and professionals are aware of their existence and benefits, AT will not be able to prove their worth and purposes. Therefore, information sharing, awareness raising and training are all crucial for successful implementation and usability of AT. In addition, difficulty of use is one of the major reasons for disuse of AT among older adults. ${ }^{60}$ Our review found that provision of community-based skills programmes has increased total performance and sense of security with the devices to a greater extent among older adults (ie, wheelchairs) in Turkey. ${ }^{32}$ Hence, the provision of training along with guidance and instruction on the use of AT will reduce the hesitancy to use AT among older adults.

Adequately trained professionals are also an important part of successful implementations and use of AT. Many developing countries including Brazil, India and Zimbabwe $^{58}$ are lacking occupational therapist (OT) and physical therapists (PT) mainly due to lower pay scales and lack of college or university training programmes. AT must be ensured to be appropriate, adaptable and high quality before distributing to older adults. They must suit the environment and the user and include adequate follow-up in order to ensure safety and efficient use. Especially when countries receive AT as donations from $\mathrm{HIC}$, they need to be assured for quality and safety. For example In Egypt, a highlighted concern is that AT are largely inappropriate, and that there are no quality standards or criteria for monitoring of these services. ${ }^{61}$ Therefore, implementing policies and programmes for training professionals to assess, provide and promote AT are relevant approaches to successfully providing AT to older adults in LMIC. Furthermore, while training OT and PT, it is important to include other experts in the field such as geriatricians to foster a multidisciplinary team approach in order to provide appropriate technologies and services. Standards and guidelines on provision, development, production and distribution of AT in LMIC must be addressed with the input of experts in the field in collaboration with other countries.

\section{Bridging the gap between AT policy and practice for older adults}

The review findings point to the existing gap between legislation and practice. Examples (table 4) were found with some legislation and policies, but whether they have resulted in significant improvement in provision of AT for all older adults in practice is unclear. This is partly due to lack of documentation or lack of evidence available in the literature. Countries that have absolutely no legislation could possibly start with ratifying the UN-CRPD. Countries that have ratified the UN-CRPD and have legislation in place could make amendments and adopt new legislation that is more focused on improving function and well-being of older adults.

Most often, planning for and responding to health and social needs of older adults falls under either the Ministry of Social Solidarity and/or Ministry of 
Health, under umbrella terms such as 'disabled care' or 'family care' or 'family medicine' (ie, in Egypt). ${ }^{48}$ This partly explains the fewer existing legislation that focus on providing AT for older adults. Legislation tends to be specific to a population group (such as the disabled), or to specific health technologies, but rarely linking the two. There is thus, a need to help countries further develop legislation that supports both production and financing of AT along with their integration with health and social services, and in particular for older adult's functional and cognitive needs.

\section{Fostering targeted research on AT}

An interesting finding of this review that offers opportunities for further research is that AT for mobility, especially canes, were the most commonly used with the least difficulty in usability among older adults. It may be explained, in part, that canes are an inexpensive, versatile and light weight mobility option that are well suited for LMIC contexts. Production costs are low and products can be made by material readily available such as wood; hence may be among the most appropriate AT in LMIC. While mobility aids provide assistance, support, strength and balance and also prevent falls, some studies ${ }^{5} 62$ have reported that mobility aids such as canes could also cause falls. Therefore, additional research is required to understand the mechanisms leading to negative consequences, as well as to better design AT and identify use and environmental measures to prevent such negative consequences along with maximising appropriateness of different AT.

The review also found that benefits of AT are rated high and disadvantages low among older adults. ${ }^{21}$ As seen in the Cambodian study, ${ }^{21}$ availability of AT to fulfil ADL have increased self-reliance and contribution to the community by physically vulnerable older adults. Improvement in social status, self-esteem, not being a burden to others, improved well-being and economic situation are among the achieved benefits of AT. Whether older adults consider AT as beneficial or not beneficial in LMIC is an important precondition for successful implementations of AT. Therefore, attitudes, aspirations and demands towards technology contribute to their usefulness and usability and perceived advantages among the users, and must be explored further prior to supplying AT to older adults.

Another observation from the review is that of the countries that had available AT, such AT were found to be suitable for the local population. For example, in Cambodia, the most common AT were different forms of seating, which enabled individuals to sit comfortably and bathe from a water source. In Cambodia, it is traditional to bathe by scooping water from a source, using a household cup or bowl and pouring it over the body. Similarly, in Turkey, walking sticks carry traditional importance in some regions, and these were one of the most used mobility aids in Turkey. When introducing AT to LMIC settings, it is important to take into account traditional and cultural values and provide AT that are likely to be accepted by the targeted population. Social acceptability of AT contributes to the usability of devices and avoids development of devices that may be stigmatised in the society. When there is more social acceptability, users are more likely to use their devices.

In addition, in future research, education and action on innovation, AT require to be seen differently, which is as highly useful products and devices that support older adults with existing impairment and disability, and as a way to prevent severe health outcomes among older adults who do not yet have disabilities.

\section{LIMITATIONS}

The systematic review retrieved a limited number of relevant publications published in peer-reviewed journals, for each country, in English. This can be partly explained by the limited research in the field of AT, especially in LMIC. In many LMIC, numerous other health issues (eg, treatment of communicable and non-communicable diseases; health insecurity) are considered as pressing priorities. Only recently did AT for older adults are becoming a health priority consideration for LMIC. At the same time, there are a number of barriers that keep LMIC from having ready access to affordable technologies. These include cost, limited funding, lack of awareness on existing AT and their benefits, cultural perceptions (or misperceptions), inappropriate environmental conditions, heterogeneity of older adults terms of functional limitations and comorbidities and a limited number of trained practitioners to train individuals on the use of AT. ${ }^{19} 48$ Lack of research conducted on the subject in resource-poor contexts strongly emphasises the need for more research on AT for older adults in LMIC.

Another limitation is that the search was limited to English language. It is possible that many countries have some research published in different languages. For example, in the case of Egypt, most documents could have been published in Arabic and not translated to English, which is possibly a reason for the lack of evidence available on Egypt. Similarly with Brazil, the authors came across material that was not published in English. Additional limitations may include those related to lack of consistency in the use of the AT terminology; and lack of awareness or knowledge base to date of the needs of older populations in the six study countries. Despite the limitations, the authors believe that the results are important and represent the most comprehensive information currently available on AT (in English) for older adults in these LMIC. 


\section{CONCLUSION AND RECOMMENDATION}

AT for ageing populations have received some attention in LMIC. AT that assisted older adults with existing impairment and disability have received more attention than AT that are designed for preventing impairment and disability among older adults who are inevitably at a high risk for impairment and disability as a result of ageing. More systematic planning and efforts are required to design, produce and ensure the availability of affordable, acceptable, accessible and adaptable AT to support older adults in meeting specific functional and cognitive limitation needs of a rapidly growing ageing population in the midst of advancements in assistive technological innovations globally.

With rapidly increasing ageing populations in LMIC, as exemplified in the six countries selected for this review, AT for the entire ageing population including older adults with existing disabilities and without existing disabilities, but are at high risk for impairment and disability, are necessary with the support of national enabling legislation. Analysis of review findings indicate the need for a comprehensive, integrated health and social system approach to increase the current availability of AT for ageing populations in LMIC. These would entail, yet not be limited to, work on: (1) promoting initiatives for low-cost AT; (2) awareness raising and capacity building on AT; (3) bridging the gap between AT policy and practice; and (4) fostering targeted research on AT.

Acknowledgements This systematic review was carried out in 2014 by the WHO Centre for Health Development, also known as the WHO Kobe Centre (WKC), scientific work stream to build the evidence base for Innovation for Healthy Ageing (IHA). The authors would like to thank the technical inputs, review and kind assistance of WHO/WKC colleagues, namely: Mr Loic Garçon, Technical Officer, WKC; Mr Amit Prasad, Technical Officer, WKC; Mr Paul Rosenberg, Technical Officer, WKC; Mr Chapal Khasnabis, Technical Officer, WHO HQ NMH/VIP/DAR; Dr Said Arnaout, Coordinator, Healthy Life Style Team, WHO Regional Office for the Eastern

Mediterranean (WHO EMRO); Egyptian team from Ain Shams University-Dr Sarah Hamza, Dr Mostafa Manar,

Dr Mousa Shereen, Dr Shawky Ahmed, Dr Rashidy Doha and Dr Hala Sakrha. They also would like to acknowledge and appreciate the support of other members of the IHA team, WKC.

Competing interests None declared.

Provenance and peer review Not commissioned; externally peer reviewed.

Open Access This is an Open Access article distributed in accordance with the Creative Commons Attribution Non Commercial (CC BY-NC 4.0) license, which permits others to distribute, remix, adapt, build upon this work noncommercially, and license their derivative works on different terms, provided the original work is properly cited and the use is non-commercial. See: http://creativecommons.org/licenses/bync/4.0/

\section{REFERENCES}

1 United Nations Department of Economic and Social Affairs. World population prospects: The 2012 revision. Secondary World population prospects: The 2012 revision 2012. http:// esa.un.org/unpd/wpp/Demographic-Profiles/index.shtm
2 United Nations. Disability-specific instruments Secondary Disability-specific instruments 2004. http://www.un.org/esa/ socdev/enable/rights/wgrefa3.htm

3 Wimo A, Prince M. World Alzheimer report 2010, 2010.

4 Hestekin H, O’Driscoll T, Williams JS, et al. Measuring prevalence and risk factors for fall-related injury in older adults in low- and middle-income countries: Results from the who study on global ageing and adult health (sage). Geneva, Switzerland University of Wisconsin/World Health Organization 2013:1-24.

5 Centers for Disease Control and Prevention. Falls in nursing homes. Secondary Falls in nursing homes 2015. http://www. cdc.gov/HomeandRecreationalSafety/Falls/nursing.html

6 World Health Organization. Opening the gate for assistive health technology: Shifting the paradigm. Secondary Opening the gate for assistive health technology: Shifting the paradigm 2014. http://www.aaate.net/sites/default/files/gate_concept_ note_for_circulation.pdf

7 Connell J, Grealy C, Olver K, et al. Comprehensive scoping study on the use of assistive technology by frail older people living in the community, Canberra, 2008:92.

8 Roelands M, Van Oost P, Depoorter A, et al. A social-cognitive model to predict the use of assistive technologies for mobility and self-care in elderly people. Gerontologist 2002;42:39-50.

9 Mann WC, Ottenbacher KJ, Fraas L, et al. Effectiveness of assistive technology and environmental interventions in maintaining independence and reducing home care costs for the frail elderly—a randomized controlled trial. Arch Fam Med 1999;8:210-17.

10 Heywood F, Turner L. Better outcomes, lower costsimplications for health and social care budgets of investment in housing adaptations, improvements and equipment: a review of the evidence. In: Department of Work and Pensions, ed. Office for Disability Issues, 2007.

11 Scott VJ, Dukeshire S, Gallagher EM, et al. A best practices guide for the prevention of falls among seniors living in the community. Ottawa: Ontario Minister of Pubic Works and Government Services Canada, 2001.

12 McConatha D, McConatha J, Dermigny R. The use of interactive computer services to enhance the quality of life for long-term care residents. Gerontologist 1994;34: 553-6.

13 Evans N, Orpwood R, Adlam T, et al. Evaluation of an enabling smart flat for people with dementia. J Demen Care 2007;15:33-6.

14 Chase CA, Mann K, Wasek S, et al. Systematic review of the effect of home modification and fall prevention programs on falls and the performance of community-dwelling older adults. Am J Occup Ther 2012;66:284-91.

15 World Health Organization. Assistive devices/technologies: what world health organization is doing. Secondary Assistive devices/technologies: what world health organization is doing 2014. http://www.who.int/disabilities/technology/activities/en/

16 World Health Organization. Ageing and life course. Secondary Ageing and life course 2012. http://www.who.int/ageing/about/ facts/en/

17 de Oliveira Assis L, Tirado MGA, de Melo Pertence AE, et al. Evaluation of cognitive technologies in geriatric rehabilitation: a case study pilot project. Wiley Inter Science, 2009.

18 da Cruz DMC, Emmel MLG. Associations among occupational roles, independence, assistive technology, and purchasing power of individuals with physical disabilities. Rev Latino-Am Enfermagem 2013;21:484-91. 
19 Mann WC, de Mello MAF. Assistive technology use by the elderly in Brazil and the United States. Top Geriatr Rehabil 2010;26:62-9.

20 Production of low cost assistive technology. Proceedings of the Fifth International Conference on Management of Emergent Digital EcoSystems. Luxembourg, Luxembourg: ACM, 2013.

21 Jones HE, Reed RA, House SJ. Water supply and sanitation access and use by physically disabled people. Leicestershire, United Kingdom: Loughborough University, 2003.

22 Salah O, Ramadan AA, Sessa S, et al. Systematic approach for design a low-cost mobility assistive device for elderly people. Int J Med Health, Pharm Biomed Eng 2011;5:36-41.

23 Jefferds AN, Beyene NM, Upadhyay N, et al. Current state of mobility technology provision in less-resourced countries. Phys Med Rehabil Clin N Am 2010;21:221-42.

24 Kumar P, Dixit U, Goyal VC. Assistive and enabling technology needs of elderly people in India: issues and initial results. 2009.

25 Biswas P, Langdon PM. A survey on technology exposure and range of abilities of elderly and disabled users in India. LNCS, 2013:23-31.

26 Manogna S, Vaishnavi S, Geethanjali B. Head movement based assist system for physically challenged. 2010 4th International Conference on Bioinformatics and Biomedical Engineering (iCBBE) Chengdu IEEE Advancing Technology for Humanity, 2009:1-4.

27 Shore SL. Use of an economical wheelchair in India and Peru: impact on health and function. Med Sci Monit 2008;14: PH71-79.

28 Shore S, Juillerat S. The impact of a low cost wheelchair on the quality of life of the disabled in the developing world. Med Sci Monit 2012;18:CR533-42.

29 Zipfel E, Cooper RA, Pearlman J, et al. New design and development of a manual wheelchair for India. Disabil Rehabil 2007;29:949-62.

30 Bengisu M. Assistive technologies for visually impaired individuals in Turkey. Off J RESNA 2010;22:163-71.

31 Şimşek TT, Yümin ET, Sertel M, et al. Assistive device usage in elderly people and evaluation of mobility level. Top Geriatr Rehabil 2012;28:190-4.

32 Asuman O, Ucsular FD. Effectiveness of a wheelchair skills training programme for community-living users of manual wheelchairs in turkey: a randomized controlled trial. Clin Rehabil 2011;25:416-24.

33 Eide AH, Nhiwathiwa S, Muderedzi J, et al. Living conditions among people with activity limitations in Zimbabwe. A representative regional survey. Oslo, Norway, 2003:136.

34 Department of Human Rights Recidency. First national report of the federative republic of Brazil on fulfillment of the provisions of the convention on the rights of disabled persons. Brazil, 2008-2010.

35 da Silva L, Inacio L. Decree 5296 of 2 december 2004. Secondary Decree 5296 of 2 december 2004 2004. http:// www.planalto.gov.br/ccivil_03/_Ato2004-2006/2004/Decreto/ D5296.htm

36 Institute for Applied Research. The rights and the social reality of people with disabilities in Brazil, Germany, France, Romania, South Korea, and Tanzania with a supplementary country survey performed in the Netherlands. Secondary the rights and the social reality of people with disabilities in Brazil, Germany, France, Romania, South Korea, and Tanzania with a supplementary country survey performed in the Netherlands
2011. http://www.diakonie-wuerttemberg.de/fileadmin/Medien/ Pdf/Ver_IntDiakoniekongress-UebersichtsstudieEngl.pdf

37 Kingdom of Cambodia. The 5th Asian \& Japan high level officials meeting on caring societies Secondary The 5th Asian \& Japan high level officials meeting on caring societies 2007. http://www.mhlw.go.jp/bunya/kokusaigyomu/asean/asean/ kokusai/siryou/dl/h19_cambodia1.pdf

38 United Nations. Convention on the rights of persons with disabilities. Secondary Convention on the rights of persons with disabilities 2006. http://www.un.org/esa/socdev/enable/ rights/convtexte.htm

39 Thomas P. Poverty reduction and development in Cambodia: enabling disabled people to play a role. Secondary poverty reduction and development in Cambodia: enabling disabled people to play a role 2005. http://r4d.dfid.gov.uk/PDF/Outputs/ Disability/PolicyProject_cambodia.pdf

40 Ministry of Social Justice and Empowerment Government of India. National policy for persons with disabilities. In: Department of Social Justice and Empowerment and Department of Disability Affairs, ed. New Delhi: India Government of India, 2006.

41 Ministry of Law Justice and Company Affairs. The persons with disabilities (equal opportunities, protection of rights and full participation) act, 1995. Secondary The persons with disabilities (equal opportunities, protection of rights and full participation) act, 1995 1996. http://socialjustice.nic.in/ pwdact1995.php

42 Government of India Ministry of Social Justice and Empowerment. Scheme of assistance to disabled persons for purchace, firtting of aids/appliances (adip scheme). In: Department of Social Justice and Empowerment and Department of Disability Affairs, ed. New Delhi, India: Government of India, 2005.

43 Giri M, Sabharwal MM, Gangadharan KR, et al. National policy for senior citizens. 2011.

44 The Republic of Turkey. Agenda item: value added tax. http:// socialjustice.nic.in/pdf/dnpsc.pdf. Secondary Agenda item: value added tax 2006. http://www.gib.gov.tr/fileadmin/ mevzuatek/uluslararasi_mevzuat/cerceve_anlasmalari/Ayrintili_ Tarama/VAT.pdf

45 European Blind Union. Six dots foundation for the blinds project. Secondary Six dots foundation for the blinds project 2008. http://6nokta.org.tr/eski/en_index.html

46 Disabled and Elderly Services. Social assistance and solidarity law. Secondary Social assistance and solidarity law. http://www. eyh.gov.tr/tr/html/8262/2.41

47 The Permanent Mission of the Republic of Zimbabwe. Permanent mission to the United Nations and other international organizations at Geneva. Geneva, 2011.

48 Hamza S, Manar M, Shereen M, et al. Assistive technologies for ageing populations. In: Lapitan JM, Marasinghe KM, eds. Egypt: Ain Shams University, 2014.

49 The Canadian Trade Commissioner Service. Export, innovate, invest- the Canadian trade commissioner service. Secondary Export, innovate, invest- the Canadian trade commissioner service 2013. http://www.tradecommissioner.gc.ca/eng/ document.jsp? $\mathrm{did}=146364 \&$ cid $=723$ \&oid=136\#2.2.

50 Japan International Cooperation Agency. Country profile on disability kingdom of Cambodia. Secondary country profile on disability Kingdom of Cambodia 2002. http://siteresources. worldbank.org/DISABILITY/Resources/Regions/East-AsiaPacific/JICA_Camboida.pdf 
51 ICRC Resource Centre. Cambodia: ICRC action continues after 30 years of presence. Secondary Cambodia: ICRC action continues after 30 years of presence 2009. http://www.icrc.org/ eng/resources/documents/update/update-cambodia-111209.htm

52 World Health Organization. The UN standard rules on the equalization of opportunities for persons with disabilities: ngo responses to the implementation of the United Nations standard rules on medical care, rehabilitation, support services and personnel training, 2002.

53 Rao SGN. Artificial limbs manufacturing corporation of India ISO 9001-2008. Geneva, Switzerland: ALIMCO, 2014.

54 United Nations (UN). Production and distribution of assistive devices for people with disabilities. Madras, India: United Nations, 1995.

55 Science for Equity Empowerment \& Development Division (SEED). Call for R \& D and technology development proposals. Secondary call for R \& D and technology development proposals 2010. http://www.dst.gov.in/whats_new/ whats_new10/tie_proposal.pdf

56 World Health Organization. The UN standard rules on the equalization of opportunities for persons with disabilities: government responses to the implementation of the United Nations standard rules on medical care, rehabilitation, support services and personnel training. WHO/DAR/011-01-8. Geneva, Switzerland: United Nations, 2001.

57 World Health Organization. Survey of needs for assistive and medical devices for older people in six countries of the WHO western pacific region: China, Japan, Malaysia, the Philippines, the Republic of Korea and Vietnam. Geneva, 2014.

58 The World Bank. World report on disability. Geneva, Switzerland: World Health Organization, 2011.

59 da Silva L, Inacio L. Presidency of the republic, civil cabinet, subchefia for legal affairs. Secondary Presidency of the republic, civil cabinet, subchefia for legal affairs 2004. http:// www.planalto.gov.br/ccivil_03/_Ato2004-2006/2004/Decreto/ D5296.htm

60 Hui-Ching Y. Elderly people's use of and attitudes towards assisitive devices.

61 Handicap International Middle East Regional Office. Taking a step forward, views from stakeholders on disability policies and services in Egypt, Jordan and Lebanon. Jordan: Handicap International, 2006.

62 Stevens JA, Thomas K, Teh L, et al. Unintentional fall injuries associated with walkers and canes in older adults treated in U. S. emergency departments. J Am Geriatr Soc 2009;57:1464-9. 